\title{
Integrated Case Studies in Teaching Introductory Mathematics Courses at College
}

\author{
Qingxia $\mathrm{Li}$ \\ Department of Mathematics and Computer Science \\ Fisk University, Nashville, Tennessee, USA \\ Xinyao Yang \\ Department of Mathematical Sciences \\ Xi' an Jiatotong Liverpool University, Suzhou, Jiangsu, China \\ URL:http://dx.doi.org/10.19044/ejes.v5no3a1
}

Doi: 10.19044/ejes.v5no3a1

\begin{abstract}
This article discusses how to integrate the directed case method to promote concept, process and application learning in an introductory mathematics course. A pretest and posttest design was applied to measure the gains on mathematics content and attitudes towards mathematics for both control and innovative sections. The innovative sections of Introductory Mathematics did much better on the posttest than the control sections even though the innovative cohort of students scored slightly lower on the pretest than did students in the control sections. As for the Attitude Toward Mathematics Inventory, the Innovation sections had "better" attitudes toward math at posttest when compared to their counterparts in the Control sections. In fact, taken together, the data suggest that a student's perception of mathematics best aligns with their interest in and enjoyment of mathematics and self-confidence in mathematics at the outset of the course. The small changes noted by use of Case studies-based learning were influenced by the small numbers in this study. However, the trend toward a positive learning impact suggests that additional cases, introduced to address other challenging concepts, may influence learning and the enjoyment of mathematics.
\end{abstract}

Keywords: Case study, pretest, posttest, directed.

\section{Introduction}

Instructors can do their best to explain how students should implement the mathematics formulas to get to the needed solution, but students are not necessarily interested in listening to instructors' attempts to explain how "cool" mathematics is. Instructors may be the "math problem master," but there is a particular real-life problem hidden here: students are not interested 
in becoming better at math because they think they don't need it (Martin, 2016). Students are easily bored of theory and formulas. Many students are more inductive than deductive reasoners, which means that they learn better from examples than from logical development starting with basic principles (Dunne \& Brooks, 2004). They realize that different areas of study depend upon the math the instructors teach. They understand that statistics, psychology, physics, computers and astronomy wouldn't be possible without math. The problem is they don't see how these specific formulas introducing in math lectures make our world a better place to live in. Pedagogy is a true art. Instructors have to experiment with different approaches and strategies until they discover the perfect method of teaching math to the particular group of students. Presented here one method that usually works in the math classroom, regardless of the students' ages: Case Studies (Martin, 2016).

Case studies are a result of instructors to develop their pedagogical repertoire: the 'why' and 'how' of teaching decisions to promote 'deep learning' and to provide opportunities for students to develop key mathematical process skills. (The National Strategies Secondary: Improving Teaching and Learning in Mathematics: Case Studies, 2008). The use of case studies can therefore be a very effective classroom technique. Teacherdirected and content-driven lecture-only classroom settings fail to engage students actively and often neglect the aspects that make mathematics interesting and applicable in solving real life problems. Although learning concepts is important for mathematics, information-packed lectures come at the expense of developing the process skills that prepare students to apply concepts in novel situations (Townend, 2001). Integrating case studies into mathematics courses is intended to develop student's problem solving, teamwork, and reflection skills and foster an interdisciplinary team teaching technique while also fostering knowledge transfer and revealing the importance of mathematics to other disciplines that the student is studying.

Through the case-study teaching method, students read realistic scenarios and are then asked to identify what questions they need to answer in order to fully understand the scenario. Compelling evidence coincides with the constructivist theory of learning, which suggests that the use of active learning methods increases both knowledge and skills because students construct their own knowledge base through the creation of a richer, more complex classroom environment that stimulates physical changes in the brain (Handelsman, et al., 2007; Dewey, 1938, NRC 2009). In contrast, traditional lecture-based classrooms may not provide students with the same ability to develop the complex network of changes to the brain that are evident when true learning takes place (Handelsman, et al., 2007). 
The Vision and Change movement for undergraduate curricula, in particular, has inspired STEM faculty to move from the traditional instructorcentered teaching methods to student-centered teaching (AAAS, 2015); the goal is to use active learning methods, such as case studies, to foster learning core concepts and scientific skills, critical thinking, and creativity (Handelsman, et al., 2007). Recently, a survey of the 1632 users of cases on the National Center for Case Study Teaching in Science (NCCSTS) site case revealed that $69 \%$ of case study users represented faculty from colleges, community colleges, and research universities, highlighting the importance of this tool for active learning in higher education.

Many undergraduates, especially traditionally underrepresented groups, avoid higher-level mathematics courses. Students who have switched from STEM majors in college report "poor teaching by faculty" as a significant reason for switching (Seymour and Hewitt 1997). Examples of 'poor' undergraduate teaching include an emphasis on memorizing facts, lack of application of concepts, and failure to encourage connections among concepts (Kardash and Wallace 2001). Aikenhead (2006) argues that one of the failures of traditional science curricula is that "students tend not to learn science content meaningfully", leading to declining student enrollment and disenchantment with science.

The purpose of this article is to evaluate the impact of integrating case studies in teaching introductory mathematics courses at the college level. These courses are taken by students whose mathematics skills and confidence are not sufficient to place into College Algebra upon undergraduate matriculation. These students need more time in order to develop their conceptual understanding of mathematics processes and gain procedural competency in using these processes.

We implemented a case studies teaching method in multiple sections of an introductory mathematics course from 2014-2016 at a historically black liberal arts institution in order to test two hypotheses: (1) the understanding of mathematics concepts would be improved if a case study was integrated into teaching, and (2) the case-study-teaching method would improve attitudes toward mathematics and increase student appreciation of the value of mathematics as they apply mathematics concepts in solving a real life problem. A Math Knowledge Test (MKT) and Attitudes Toward Mathematics Inventory (ATMI) were administered to test the two hypotheses using a pretest-posttest method. In section 2, we discuss the format and delivery of the case studies developed for this course. In section 3, we demonstrate the methodology used to collect the data on the two measures and the results of data analysis. We discuss the results in section 4 and the identifiable advantages are summarized in section 5 . 


\section{Case Studies}

\subsection{Background}

These cases were developed for college students who are underprepared for college level math courses, do not appreciate the value of mathematics, and are registered in an introductory mathematics course. The purpose of applying case studies in teaching mathematics is to address the following questions: (1) How do these case studies help students to improve their attitudes towards mathematics? (2) How do these case studies promote students' deeper understanding of the assumptions that need to be in place in order for this math theorem to be effective? Four cases were developed for this course in the sections of Linear equations, Linear inequalities, Fractions, and Factoring.

\subsection{Format}

The design of these cases is highly directive. All the questions that accompany these cases are written in a free-response format so that students understand the concept and show their work instead of guessing the answers in a multiple-choice format.

\subsection{Delivery}

Students received the entire case study at the beginning of a twolecture series. Students performed the analysis of the case entirely in the first class, and were free to work individually or in groups. During the first class period, students in each group used 5-10 minutes to read the case study, highlight any parts that they think are confusing and think about what procedures they should take to move forward. Then they spent 10-15 minutes discussing the case study, being careful to explore the significance of the features that teachers have identified in the lectures. Finally, they made the connections between the case study and the learning objective in this area. An in-class poster presentation of the case was then held during the following class period. The rationale for this "front-ended" delivery is based on findings that meaningful understanding occurs when students are initially presented with a problem that drives their learning (Norman \& Schmidt, 1992). During the second class, each student prepared a poster presentation describing the concepts and methodology. Student were free to ask questions about their peers' posters, share the ideas, and critique their peers. The poster presentation provided students opportunities to mingle and interact with each other. The instructor conducted a review at the end of the class period to provide a summative opportunity for students to receive corrective feedback (Norman \& Schmidt, 1992), pointing out common errors and summarizing the underlying mathematics concepts. Overall, the goal of this format was to spark student curiosity about the real life applications of the mathematics concepts. 


\subsection{Assessment}

The poster was counted as part of the course grade. The overall grades depended on the peer evaluation of the whole class. The peer evaluation grading is adapted from the evaluation techniques in case study teaching (Herreid, 2001). This peer evaluation can be done anonymously to decrease peer pressure. In a group of four students, each student was given 30 points to distribute to their teammates according to their relative contributions to responding to the case. The rules are attached below:

- $\quad$ No student can give any teammate more than 15 points, but with no lower limit on the given points.

- $\quad$ Each student does not need to use up all of the given 30 points.

- $\quad$ Students should not feel compelled to give classmates a minimum grade (i.e. a grade that they don't deserve).

- $\quad$ Students should indicate the reasons why a teammate was assigned less than or greater than 5 points.

The effort ratio was then calculated as the ratio of the score that each student was given from his/her teammates over the total of 30 possible points. The final case score, as a percent, was calculated by multiplying the effort ratio by 100. For example, if the sum of peer evaluation score is 21 , Then the score for this student is $21 / 30 * 100=70 \%$.

\section{Methods.}

\subsection{Participants}

Participants were 108 students (31 males and 77 females) ranging in age from 17 to $22(\mathrm{M}=18.81, \mathrm{SD}=0.75)$ recruited at a historically black university. Participants were recruited in Introductory Mathematics classes in Fall 2014, 2015 and 2016. The sample included 2 white students, 104 AfricanAmerican students and 2 students identifying as other ethnicities (international students).

\subsection{Instruments}

Each participant received a packet containing four demographic questions (e.g. age, gender), a 25-question multiple choice Math Knowledge Test (MKT), which is developed by the author and is a course-specific test of students' understanding of the core concepts and skills covered by the course, and an Attitudes Toward Mathematics Inventory (ATMI), which is a 40-item instrument that was developed by Tapia and Marsh (2004) who examined its psychometric properties and factorial structure. A 5-point Likert response scale is used (strongly agree, agree, neither agree nor disagree, disagree, strongly disagree). There are four subscales (Tapia \& Marsh, 2004).

i.Enjoyment of Math (10 items) - "the degree to which students enjoy working (on) mathematics." 
ii.Motivation (5 items) - "interest in mathematics and desire to pursue further studies in math."

iii.Self-confidence (15 items) - "confidence and self-concept of (one's) performance in math."

iv.Value (10 items) -- "beliefs about the usefulness, relevance and worth of math to their lives."

In order to ensure equivalence of students in the Control and Innovative conditions, we administered a MKT and ATMI on the first day of class for both conditions. At the end of the class, learning outcome measures included scores on posttests for both MKT and ATMI, passing and retention rates, and exams including the final exam.

\subsection{Course Type}

The study will use a quasi-experimental design comparing students in the Control and Innovative sections. Two sections of Math 100 in Fall 2014 were taught under traditional lectures. Of the three sections of Math 100 in Fall 2015 (Sections 1, 2, and 4), the innovative instructional practices were implemented only in Section 1. Both of the two sections in Fall 2016 were taught with the innovative case studies. Sections 2 and 4 in Fall 2015 and the two sections in Fall 2014 serve as the Control group while Section 1 in Fall 2015 and two sections in Fall 2016 serve as the Innovative group.

\subsection{Data Analysis}

Data were analyzed for two measures, both of which were administered at the beginning and end of each semester in Fall 2014, 2015 and 2016. Data were available for 62 students in the Control group and 46 students in the Innovative groups. Not all students had both pre- and posttest data for several possible reasons: dropping the class, adding the class after either the math attitudes or knowledge pretests were administered, or being absent from class on the day that a measure was administered. This resulted in final sample sizes of 38 students in the Innovation section and 44 in the Control sections. The percentages of students with complete data in the innovation and control sections were $83 \%$ and $71 \%$, respectively. 
Table 1. Completeness of Math Knowledge and Attitudes Data for Students in the Innovation and Control Sections

\begin{tabular}{|c|c|c|c|c|}
\hline \multirow{2}{*}{$\begin{array}{l}\text { Completeness of math } \\
\text { knowledge data }\end{array}$} & \multicolumn{3}{|c|}{ Completeness of math attitudes data } & \multirow[b]{2}{*}{ Total } \\
\hline & $\begin{array}{l}\text { Both pre- and } \\
\text { posttest }\end{array}$ & Pretest only & $\begin{array}{l}\text { Posttest } \\
\text { only }\end{array}$ & \\
\hline \multicolumn{5}{|l|}{$\begin{array}{l}\text { Innovation Sections [Case } \\
\text { Studies introduced] }\end{array}$} \\
\hline Both pre- and posttest & $38(83 \%)$ & $0(0 \%)$ & $0(0 \%)$ & 38 \\
\hline Pretest only & $0(0 \%)$ & $5(11 \%)$ & $0(0 \%)$ & 5 \\
\hline Posttest only & $0(0 \%)$ & $0(0 \%)$ & $3(6 \%)$ & 3 \\
\hline \multicolumn{5}{|l|}{ Control Sections } \\
\hline Both pre- and posttest & $44(71 \%)$ & $0(0 \%)$ & $0(0 \%)$ & 44 \\
\hline Pretest only & $0(0 \%)$ & $13(21 \%)$ & $0(0 \%)$ & 13 \\
\hline Posttest only & $0(0 \%)$ & $0(0 \%)$ & $9(8 \%)$ & 9 \\
\hline
\end{tabular}

\subsection{Overall Results.}

1. All analyses focused on students with both pretest and posttest data on the two math measures.

2. For the math attitudes measure, students' responses were coded as follows: strongly agree $=+2$; agree $=+1$; neither agree nor disagree $=0$; disagree $=-1$; and strongly disagree $=-2$. Students' average scores on the total ATMI scale and each of its four subscales range from -2 to +2 .

3. For the math knowledge measure, there were 25 items, all of which were scored as correct (1) or incorrect (0). A student's overall score for either the pretest or the posttest could then range from 0 (none were correct) to 25 (all questions were answered correctly). For the subset of items targeted explicitly at math knowledge/skills on which the innovative practices focused, scores could range from 0 to 5 .

4. The statistical comparison between the Case Studies Innovation versus Control was performed for both the pretest and posttest on all outcome variables.

a. These comparisons were seriously underpowered due to small sample sizes, resulting in a reduced ability to find an effect, especially small effects when they exist.

b. In addition, because several comparisons (42 pairwise comparisons) were required, a stricter criterion $(p<0.001)$ was needed to declare statistical significance in order to avoid taking advantage of chance. This also decreased the ability to describe a difference as statistically significant.

5. Effect sizes were then calculated for each pairwise comparison. These were used to identify where differences might exist and their magnitude. It should be noted, however, that caution should be used in interpreting any differences, given the wide confidence intervals around these effect sizes due 
in part to the considerable variation within each section on an outcome (e.g., standard deviations often were greater than their respective means). ${ }^{1}$

6. Figure 1 and Table 2 present the average pretest and posttest scores for the Math Knowledge test. Looking at Figure 1, the solid line represents the section that employed the innovative teaching practices; the control sections not exposed to these methods are denoted by dashed lines.

a. At the beginning of the semester, students' knowledge of the key concepts that would be covered by the course attitudes toward math was fairly minimal. The average number of items that were answered correctly was somewhat lower in the Innovation course (mean $=4.9$ ) as compared to that in control course $($ mean $=6.1)$. These translate into effect size of -0.39 .

b. In both Control and Innovative sections, the average scores on the posttest were considerably higher (see Figure 1). However, whereas students in the Innovation course scored lower on the pretest, they outperformed the Control sections. It also should be noted that although all the sections scored similarly on the pretest, there was much less positive change for the Control sections at the end of the course.

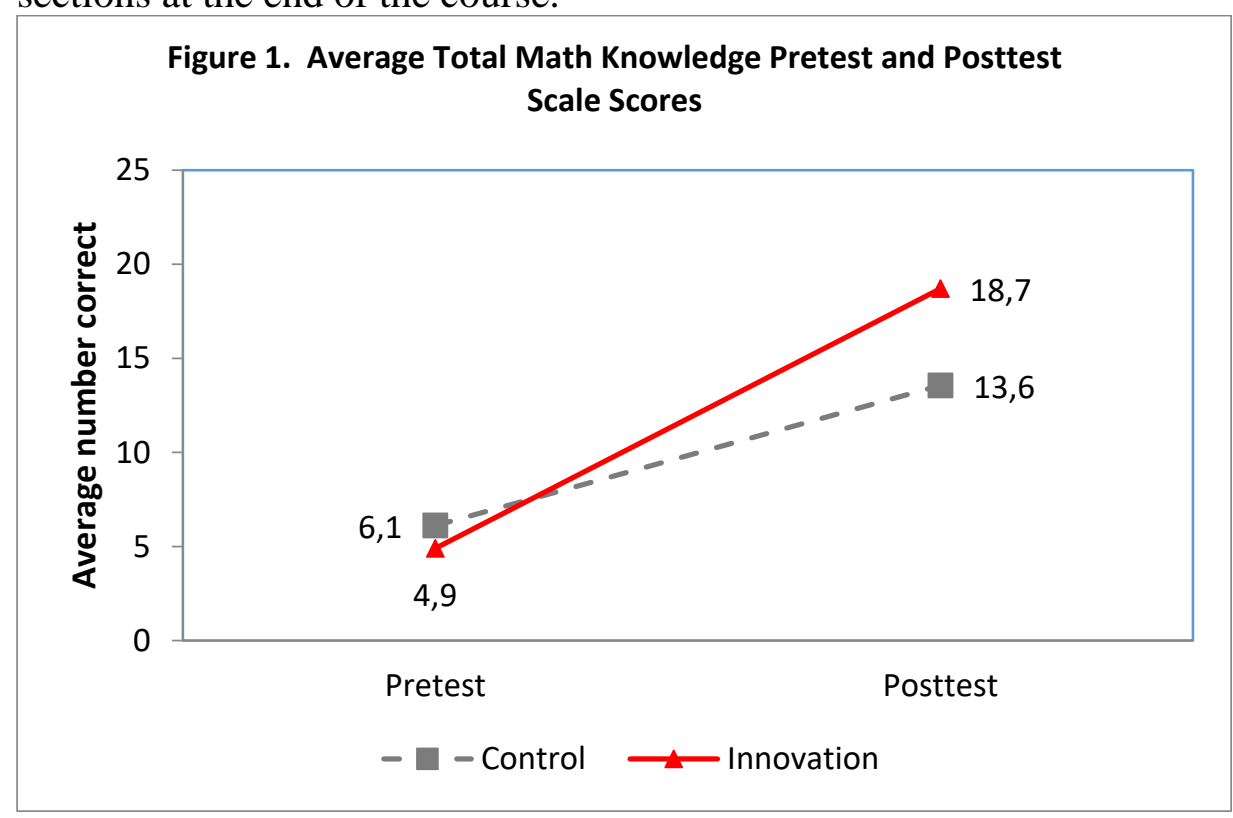

c. As can be seen in Table 2, the difference between the Innovation section and Control sections was large $(\mathrm{ES}=1.28)$.

1 Using the same criteria used to describe the magnitude of group differences as we do for effect sizes, an effect size of $0.25-0.49$ is viewed as a small difference, $0.50-0.79$ as a medium difference, and 0.80 and above as a large difference. 
Table 2. Group Differences on Math Knowledge Test

\begin{tabular}{|l|l|l|l|}
\hline $\begin{array}{l}\text { Timing of } \\
\text { administration }\end{array}$ & Innovation & Control & $\begin{array}{l}\text { Innovation vs. } \\
\text { Control }\end{array}$ \\
\hline & Mean & Mean & ES \\
\hline All 25 items & & & -0.39 \\
\hline Pretest & 4.90 & 6.11 & 1.28 \\
\hline Posttest & 18.70 & 13.56 & \\
\hline
\end{tabular}

7. Figure 3 and Table 3 show the results for the total attitude scale for the all sections in Fall 2014, 2015 and 2016.

a. At the beginning of the semester, student attitudes toward math hovered around a general neutral perspective. Similar to the results for the Math Knowledge test, the Innovation section had the lowest mean $(-0.13)$.

b. $\quad$ By the end of the semester, attitudes had shifted toward being more positive. In the Innovation sections, the mean increased from -0.13 to 0.59 . An increase also occurred in the Control sections where the mean rose from 0.04 at the pretest to 0.16 at the posttest.

c. Overall, the difference in math attitudes was significant between students in the Innovation section versus those in Control sections ( $E S=0.45)$.

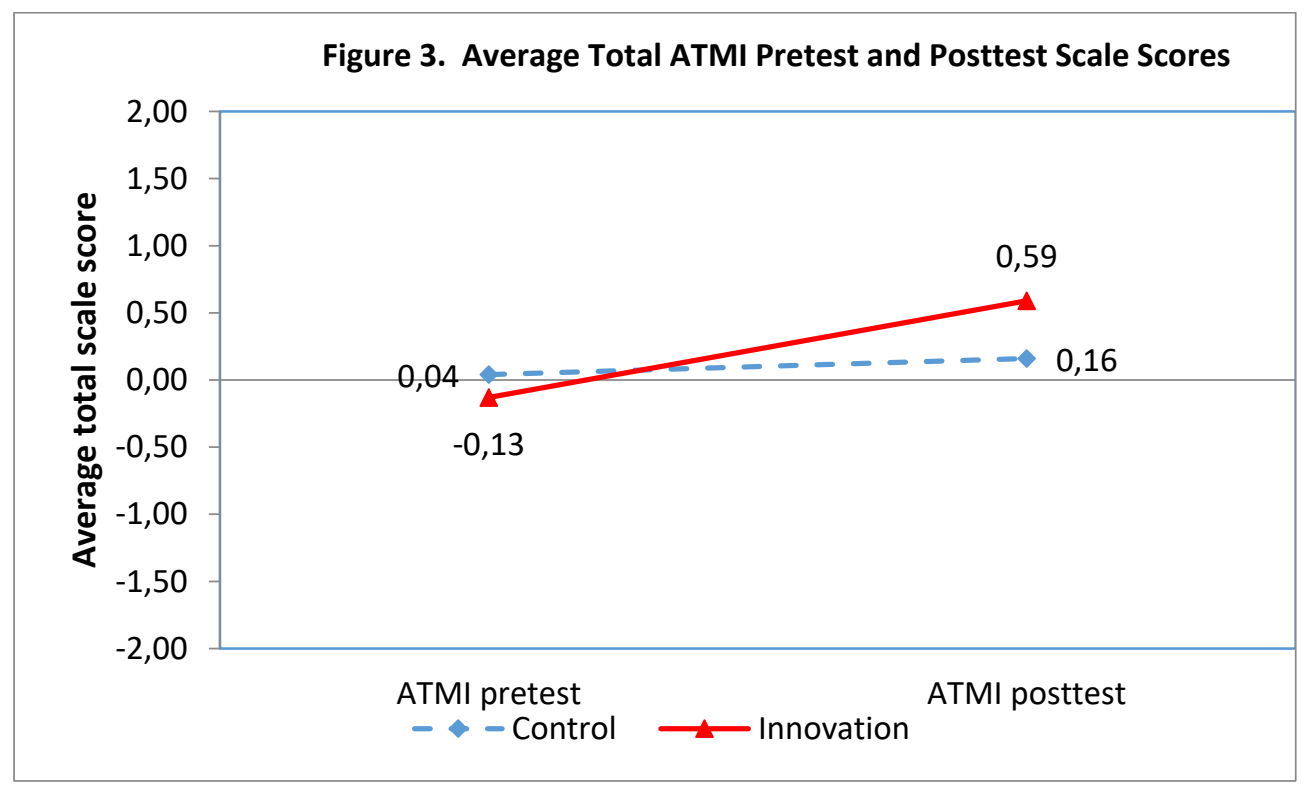

c. The shift in positive attitudes appears to be primarily due to increases on both the Enjoyment of Math and Self-confidence in Performance subscales (see Table 3). The effect sizes for the comparisons between the Innovation and Control sections were between 0.47 and 0.48 on these two subscales. 
Table 3. Group Differences on Attitudes Toward Math Inventory

\begin{tabular}{|l|l|l|l|}
\hline $\begin{array}{l}\text { Scale and timing of } \\
\text { administration }\end{array}$ & Innovation & Control & $\begin{array}{l}\text { Effective Sizes for } \\
\text { Innovation } \\
\text { Control }\end{array}$ \\
\hline & Mean & Mean & ES \\
\hline Total scale & & & \\
\hline Pretest & -0.13 & 0.04 & -0.21 \\
\hline Posttest & 0.59 & 0.16 & 0.45 \\
\hline Value of math & & & \\
\hline Pretest & 0.51 & 0.84 & -0.47 \\
\hline Posttest & 1.04 & 0.69 & 0.42 \\
\hline Enjoyment of math & & & \\
\hline Pretest & -0.27 & -0.04 & -0.22 \\
\hline Posttest & 0.55 & 0.06 & 0.47 \\
\hline $\begin{array}{l}\text { Motivation to pursue } \\
\text { math }\end{array}$ & & & \\
\hline Pretest & -0.58 & 0.23 & -0.90 \\
\hline Posttest & 0.16 & -0.14 & 0.26 \\
\hline $\begin{array}{l}\text { Self-confidence in } \\
\text { math performance }\end{array}$ & & & \\
\hline Pretest & -0.30 & -0.50 & 0.23 \\
\hline Posttest & 0.45 & -0.03 & 0.48 \\
\hline
\end{tabular}

\section{Discussion}

In many educational situations, students' pretest standing on a related measure influences their standing on the same measure at posttest. As such and because the three sections often differed in math knowledge and attitudes toward math at the pretest, OLS regressions were performed on both the Math Knowledge and ATMI scores. Predictors used were the student's pretest standing on the measure as well as whether the student was in the Innovation sections or in the control sections. [Note. Because of the small sample sizes and for ease of interpretation, the sections were combined for these analyses.] These analyses better examine the influence of the innovative instructional methods, controlling for students' pretest standing, and thus can better provide support for the role of the Innovation in terms of the outcomes.

a. After controlling for students' standing on the pretest, the influence of the Innovation section remained (see Table 4). On average, students in the Innovation sections answered $4.46(18 \%)$ more of the 25 items than students in the Control sections. The effect size, adjusted for pretest standing, was still large (adjusted ES = 1.15).

b. Students' attitudes toward math at the beginning of the semester may have had a larger influence on their attitudes at the end of the semester than did whether they were enrolled in the Innovation section. As shown in Table 
4, the average score on the posttest ATMI was 0.39 (8\%) higher for students in the Innovation section.

Table 4. Results of Regressions on Posttest Scores for Math Knowledge and ATMI

\begin{tabular}{|l|l|l|l|}
\hline Predictor & Estimate & SE & $P$ \\
\hline Math Knowledge & & & \\
\hline Intercept & & & \\
\hline Pretest & 11.67 & 1.77 & $<.001$ \\
\hline In the Innovation section (1 = yes, 0= no) & 0.54 & 0.24 & .04 \\
\hline & 4.46 & 1.63 & .01 \\
\hline Attitudes toward Math Inventory & & & \\
\hline Intercept & & & \\
\hline Pretest & 0.29 & 0.16 & 0.09 \\
\hline In the Innovation section $(1=$ yes, $0=$ no) & 0.70 & 0.17 & $<.001$ \\
\hline
\end{tabular}

\section{Conclusion}

In summary, the innovative sections of Introductory Mathematics mostly did better by the end of the course than the control sections even though the innovative cohort of students scored slightly lower on the pretest than did students in the control sections. As for the attitude toward mathematics, the Innovation sections had "better" attitudes toward math at posttest when compared to their counterparts in the Control sections. In fact, taken together, the data suggest that a student's perception of mathematics best aligns with their interest in and enjoyment of mathematics and self-confidence in mathematics at the outset of the course.

The small changes noted by use of Case Studies-based learning were influenced by the small numbers in this study. However, the trend toward a positive learning impact suggests that additional cases, introduced to address other challenging concepts, may influence learning and the enjoyment of mathematics. For these cases, the time burden of a poster presentation may be substituted by other group-based outputs, allowing for more cases to be introduced during a single semester. Intentionally developing cases that relate to content students will encounter in other mathematics and science courses, particularly in biology, may foster a greater appreciation of the value of mathematics and its broad application.

\section{Acknowledgement:}

Funding for this project was provided from grants by the National Science Foundation [grant number HRD 1332284 and 1547757]. The author would like to thank Dr. Georgine Pion for the data analysis and Dr. Lee E Limbird, for review of the manuscript. 


\section{References:}

1. Aikenhead, G.S., (2006). Science Education for Everyday Life: Evidence-based Practice. New York, NY: Teachers College Press, Columbia University.

2. American Association for the Advancement of Science (AAAS). (2015). Vision and change in undergraduate biology education: Chronicling change, inspiring the future. Retrieved from AAAS website: http://visionandchange.org/chronicling-change

3. Blosser, P. E. (1988). Teaching Problem Solving--Secondary School Science. EMI-ERIC Clearinghouse for Science, Mathematics, and Environmental Education 2.

4. Dewey, J. (1938). Experience and education. New York, NY: MacMillan.

5. Dunne, D. and Brooks, K. (2004). Teaching with Cases. Halifax, NS: Society for Teaching and Learning in Higher Education.

6. Gallagher, S.A., Stepien, W.J., Sher, B.T., \& Workman, D. (1995). Implementing Problem-based learning in science classrooms. School Science and Mathematics, 95(3), 136-146.

7. Handelsman, J., Miller, S., \& Pfund, C. (2007). Scientific teaching. New York, NY: W. H. Freeman.

8. Herreid, C. F., (2001). When Justice Peeks, Evaluating students in case study teaching. Journal of College Science Teaching, 30 (7), 430-433.

9. Kardash, C.M., and Wallace, M.L., (2001). The Perceptions of Science Clases Survey: What Undergraduate Science Reform Efforts Really Need to Address. Journal of Educational Psychology, 93 (1), 199-210.

10. Krynock, K.B., and L. Robb. (Fall 1996). Is problem-based learning a problem for your Curriculum?" Illinois School Research and Development Journal 33 (1), 21-24.

11. Kuh, G. (2008). High-Impact Educational Practices, Washington D.C.: Association of American Universities and Colleges.

12. Martin, J., (2016). Why Should We Use Case Studies in the Math Classroom? Retrieved from http://www.gettingsmart.com/2016/04/why-should-we-use-casestudies-in-the-math-classroom/

13. Norman, G.A., and H.G. Schmidt. (1992). The psychological basis of problem-based learning: A review of the evidence. Academic Medicine, 67, 557-565.

14. Seymour, E., and Hewitt, N.M., (1997). Talking about Leaving: Why Undergraduates Leave the Science. Boulder, CO: Westview Press.

15. Tapia, M. \& Marsh G. E. (2004). An Instrument to Measure Mathematics Attitudes. Academic Exchange Quarterly, 8(2), 16-21. 
16. Townend, M.S., (2001). Integrating Case Studies in Engineering Mathematics: A Response to SARTOR 3. Journal of Teaching in Higher Education, 6 (2), 203-215. 